\title{
OPEN Systemic nicotine enhances opioid self-administration and modulates the formation of opioid-associated memories partly through actions within the insular cortex
}

\author{
Gregory C. Loney, Christopher P. King \& Paul J. Meyer ${ }^{\circledR}$
}

Habitual use of nicotine containing products increases propensity to misuse prescription opioids and its prevalence is substantially increased in individuals currently involved in opioid-treatment programs. Nicotine enhances self-administration of many classes of drugs in rodents, though evidence for direct effects on opioids is lacking. We sought to measure the effects of nicotine pretreatment on the reinforcing efficacy of opioids in both self-administration and contextual conditioning paradigms. First, we measured the effect of systemic nicotine pretreatment on self-administration of two opioids. Additionally, we measured the degree to which systemic nicotine pretreatment impacts the formation of morphine-associated contextual memories in conditioned taste avoidance and place preference paradigms. Given the involvement of the insula in the maintenance of substance abuse, its importance in nicotine addiction, and findings that insular inactivation impairs contextual drug conditioning, we examined whether nicotine administered directly to the insula could recapitulate the effects of systemic nicotine. We demonstrate that systemic nicotine pretreatment significantly enhances opioid self-administration and alters contextual conditioning. Furthermore, intra-insula nicotine similarly altered morphine contextual conditioning by blocking the formation of taste avoidance at all three morphine doses tested $(5.0,10$, and $20 \mathrm{mg} / \mathrm{kg}$ ), while shifting the dose-response curve of morphine in the place preference paradigm rightward. In conclusion, these data demonstrate that nicotine facilitates opioid intake and is partly acting within the insular cortex to obfuscate aversive opiate memories while potentiating approach to morphine-associated stimuli at higher doses.

Concurrent nicotine use is significantly correlated with substance abuse across a wide variety of commonly abused drugs, including opioids ${ }^{1-5}$. Approximately $83-95 \%$ of individuals currently involved in an opioid-treatment program (OTP) are current users of nicotine and a positive relationship exists between nicotine use and propensity to misuse prescribed opioid $s^{6-8}$. Because initiation of nicotine use typically precedes illicit drug use ${ }^{9}$, nicotine-containing products may either promote the development of opioid-use disorders (OUDs) or exacerbate their severity. There is emerging evidence that nicotinic and opioid receptor systems interact in a manner that alter the response to opioid-associated cues in a fashion that may promote vulnerability to OUDs ${ }^{10-13}$. Specific mechanisms and brain areas involved in these effects of nicotine in preclinical models have not been fully elucidated. Furthermore, while concurrent nicotine use increases methadone consumption in clinical populations ${ }^{14}$ there are minimal reports of direct effects of nicotine pretreatment on opioid self-administration in preclinical models.

The formation and recall of drug-associated memories is indispensable for the development and maintenance of substance use disorders (SUDs). Mnemonic representations of the past reinforcing and aversive properties of drug administration and withdrawal can be elicited by cues and contexts that were present during drug episodes and can serve to elicit either approach or avoidance ${ }^{15-18}$. Importantly, there is ample evidence for nicotine in modulating the development, strength, and recall of drug-associated memories across multiple classes of abused drugs and across multiple learning paradigms designed to measure the impact of the reinforcing and aversive 
effects of drug administration ${ }^{19-23}$. Specifically, acute nicotine pretreatment robustly increases the incentive properties of discrete drug-predictive cues ${ }^{19,24-26}$ and this enhancement is likely dependent on nicotinic activity within the midbrain dopaminergic circuitry, particularly the ventral tegmental area ${ }^{27,28}$. There is emerging evidence that, unlike the effects seen on discrete stimuli, nicotine pretreatment may impair the strength of drug-associated contextual memories. Acute systemic and intracranial nicotine pretreatment limits the acquisition of conditioned place preference (CPP) to lower doses of morphine and cocaine $\mathrm{e}^{11,29,30}$ and conditioned place avoidance from naloxone-precipitated morphine withdrawal ${ }^{31,32}$. Additionally, across multiple commonly abused substances, acute systemic nicotine pretreatment impairs the formation of conditioned taste avoidance (CTA) following contextual presentation of a taste stimulus that predicts passive administration of the drug stimulus $^{12,22,23}$. Interestingly, at least for ethanol, discrete presentation of the taste stimulus, wherein the taste is contingently yoked to drug administration, results in a conditioned preference ${ }^{33-35}$ further suggesting that the circumstances of presentation of a specific cue affect its associative properties ${ }^{36}$ and thus the relative contribution of potential brain areas and neurotransmitter systems.

One brain area in which nicotine may act to impair the formation of drug-associated contextual memories is the insular cortex (IC). The IC is a heterogeneous cortical structure that sends and receives numerous projections associated with sensory information and limbic processing and as such represents an area critical for integration of sensory and motivational functions ${ }^{37}$. As a whole, the IC is critical for the acquisition and expression of both reinforcing and aversive drug-associated contextual memories and is heavily implicated in nicotine addiction ${ }^{38-40}$. Inactivation of many IC subareas can affect the self-administration of commonly abused drugs $^{41-43}$, the strength of drug-induced $\mathrm{CTA}^{44}$, as well as the strength of both the $\mathrm{CPP}^{45}$ induced by drugs and the conditioned place avoidance induced by drug withdrawal ${ }^{46}$. Activation of nAchRs on IC GABAergic interneurons facilitates synaptic depression at layer $\mathrm{V}$ pyramidal neurons, the primary excitatory output of the IC to subcortical structures ${ }^{47-49}$. Morphine regulates the activity of inhibitory interneurons within the frontal cortex and these actions on interneurons appear to be required for morphine contextual place conditioning ${ }^{50}$. As such, nicotine pretreatment within the IC may have functional consequences on the formation and/or strength of opioid-associated memories. Specifically, the impairment of synaptic potentiation within the insular cortex by nicotinic-modulation of GABAergic interneurons may result in a deficit in learning about drug-associated contexts in a manner that promotes the development of SUDs.

Given the large overlap in nicotine and opioid dependence in clinical populations and the relative paucity of experimental data on the effects of nicotine on self-administration of opioids in preclinical models we examined the effects of nicotine on opioid intake and contextual conditioning. Furthermore, we focused on the insular cortex because it is critical for learning drug-associated contexts, is involved in the maintenance and development of substance abuse, is critical for the abuse-related effects of nicotine addiction ${ }^{41,51}$, and insular plasticity appears to be modified through application of nicotine. First, we sought to demonstrate that nicotine pretreatment has functional consequences on opioid self-administration by examining whether it enhanced intake of the ultra-short-acting synthetic opioid remifentanil in a fixed-ratio intravenous self-administration paradigm (IVSA). We also tested the effects of nicotine on a longer acting opiate in morphine. Next we examined the effects of systemic nicotine pretreatment on contextual conditioning by the interoceptive properties of multiple doses of morphine in CTA and CPP paradigms. Finally, we aimed to examine whether intra-insular delivery of nicotine similarly altered contextual conditioning with morphine as would be predicted by recent in vitro and behavioral studies ${ }^{11,21,47}$.

\section{Results}

Experiment 1. Relative to responding under saline conditions, pre-treatment with nicotine significantly increased the number of active lever presses $\left(F_{(1,8)}=20.83, P<0.01\right)$ resulting in an increased number of remifentanil infusions $\left(F_{(1,8)}=22.19, P<0.01\right)$ while having no effect on the number of inactive lever presses $(P=0.70$; Fig. 1A). Analysis of the cumulative intake of remifentanil across the two-hour session grouped into 5-min bins revealed that nicotine pretreatment, relative to saline, significantly elevated remifentanil intake beginning at $40 \mathrm{~min}$ and remained elevated throughout the remainder of the two-hour session $\left(F_{(23,184)}=26.00, P<0.001\right.$; Fig. 1B). Similarly, nicotine pretreatment significantly enhanced active responding for morphine $\left(F_{(1,8)}=12.77\right.$, $P<0.01)$ with no effect on inactive responding $(P=0.52)$ leading to an overall enhancement of morphine intake $\left(F_{(1,8)}=12.76, P<0.01\right.$; Fig. 1C). Analysis of cumulative morphine intake revealed that nicotine increased morphine intake beginning at $10 \mathrm{~min}$ and remained elevated throughout the session $\left(F_{(23,184)}=4.32, P<0.001\right.$; Fig. 1D).

Experiment 2. Conditioned taste avoidance. Systemic nicotine pretreatment $(0.4 \mathrm{mg} / \mathrm{kg})$ significantly attenuated the development of CTA to all doses of morphine tested $(5.0,10$, and $20 \mathrm{mg} / \mathrm{kg})$, relative to saline pretreatment (Fig. 2A,B). A Drug $\times$ Dose $\times$ Day ANOVA conducted on the intake of the CS + during the acquisition phase revealed a significant 3 -way interaction $\left(F_{(9,192)}=2.40, P<0.05\right)$. Post-hoc analyses indicated that nicotine-treated rats consumed significantly more saccharin than saline-treated rats on day 4 of conditioning with $5.0 \mathrm{mg} / \mathrm{kg}$ morphine, days 3 and 4 of conditioning with $10 \mathrm{mg} / \mathrm{kg}$ morphine, and days 2, 3, and 4 of conditioning with $20 \mathrm{mg} / \mathrm{kg}$ morphine (Ps $<0.05$; Fig. 2A).

Analyses of the expression tests (Fig. 2B) supported the acquisition data. A Drug $\times$ Dose ANOVA conducted on the preference for the $\mathrm{CS}+$ in the absence of any further drug administrations revealed a significant 2-way interaction $\left(F_{(3,64)}=3.19, P<0.05\right)$. Post-hoc analyses determined that, compared to unconditioned controls, both nicotine- and saline-treated rats demonstrated a significant decrease in the preference for saccharin at all three doses of morphine $(P s<0.05)$. Importantly, nicotine-treated rats displayed a significantly larger preference for saccharin following conditioning with all three doses of morphine relative to saline-treated rats $(P s<0.05$; 

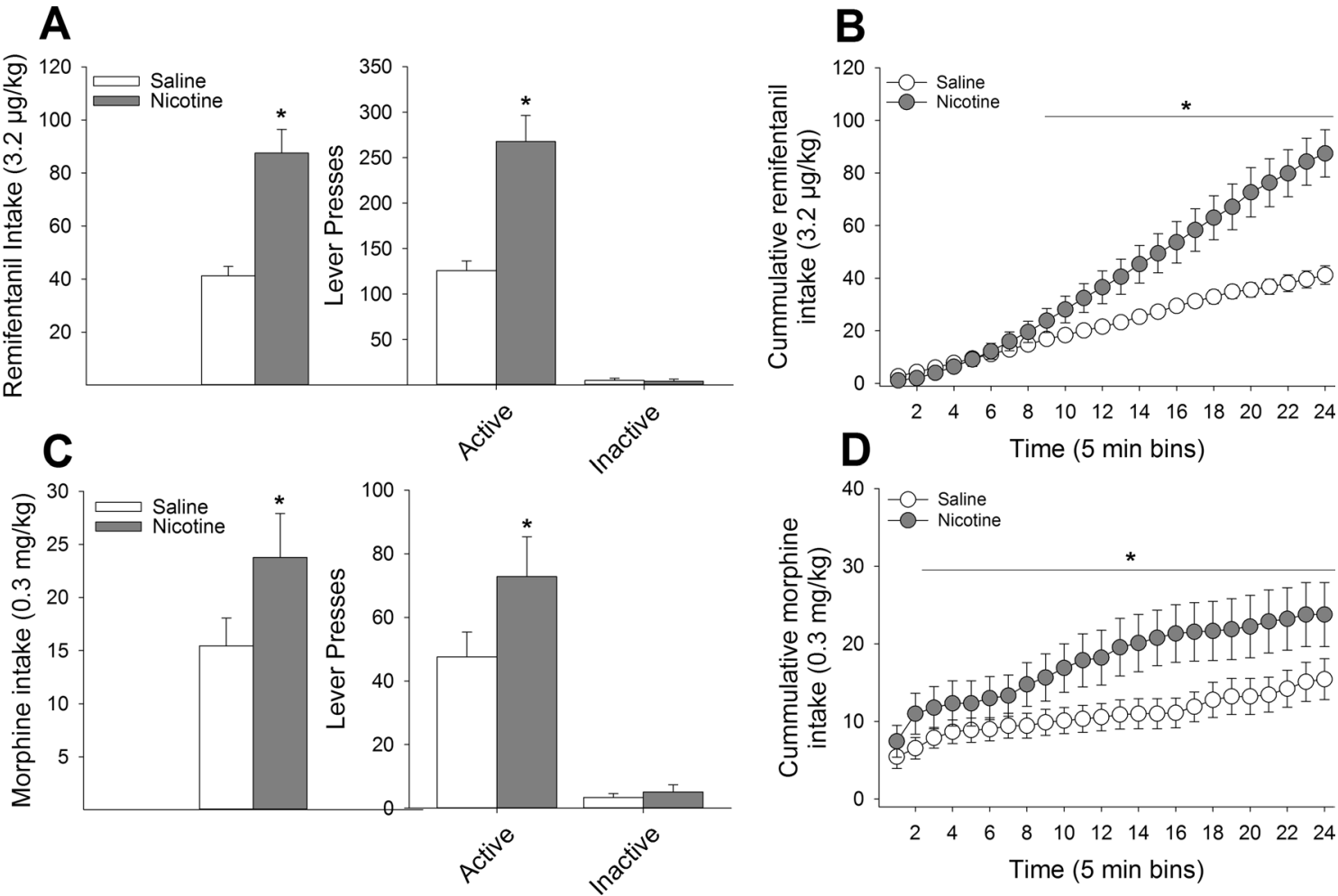

Figure 1. Systemic nicotine pretreatment enhances opioid self-administration. (A) In a within-subjects design, pretreatment with $0.4 \mathrm{mg} / \mathrm{kg}$ nicotine significantly increased the number of remifentanil infusions relative to saline pretreatment with no impact on responding on the inactive lever. (B) Time course analysis revealed that nicotine significantly increased remifentanil intake around the $40^{\text {th }}$ minute of the session. Nearly identical effects were observed with regards to nicotine pretreatment on morphine intake, with significant nicotine-induced increases in intake $(\mathbf{C})$ such that nicotine increased morphine intake at the 10th minute of the session and remained elevated throughout the session $(D)$. ${ }^{*}$ s indicate significant group differences $(P<0.05)$.

Fig. 2B). There was no effect of nicotine on the preference for saccharin in the unconditioned controls suggesting that the any potential aversive properties of nicotine were likely not impacting conditioning within the present experiments.

Conditioned place preference. Systemic nicotine administration $(0.4 \mathrm{mg} / \mathrm{kg})$ altered the pattern of expression of CPP following conditioning with multiple doses of morphine (Fig. 2C). A Drug $\times$ Dose ANOVA conducted on the change in expression for preference of the drug-paired context revealed a significant 2-way interaction $\left(F_{(3,64)}=2.94, P<0.05\right)$. Post-hoc analyses revealed that nicotine pretreatment shifted the dose-response curve to the right, relative to saline pretreatment. Specifically, saline-treated rats showed a significant enhancement of CPP following conditioning with 5.0 , and $10 \mathrm{mg} / \mathrm{kg}$ morphine. Nicotine-treated rats failed to show a significant CPP to morphine at all doses except for the highest dose tested $(20 \mathrm{mg} / \mathrm{kg})$, a dose at which saline-treated rats did not display CPP. The CPP occurring following conditioning with $10 \mathrm{mg} / \mathrm{kg}$ in nicotine-treated rats did not survive Bonferroni correction. Peak conditioning in saline-treated rats occurred at the $5.0 \mathrm{mg} / \mathrm{kg}$ dose and peak conditioning in nicotine-treated rats occurred at the $20 \mathrm{mg} / \mathrm{kg}$ dose. There was a main effect of nicotine on locomotor activity (Fig. 2D) during morphine conditioning $\left(F_{(1,64)}=7.86, P<0.01\right)$ but no interactive effects between nicotine and morphine.

Experiment 3. Histology. Only animals for which we could determine that both cannulae were correctly placed into the insular cortex were included in statistical analyses. Figure $3 \mathrm{~A}$ represents the placement of all injection sites across each experimental condition. Figure 3B depicts a representative image of a thionin-stained coronal section illustrating cannulae and injector track marks targeting the agranular insular cortex.

Conditioned taste avoidance. Nicotine $(4 \mu \mathrm{g})$ infused directly into the insular cortex completely blocked the acquisition of morphine-induced CTA at all three doses of morphine (5.0, 10, and $20 \mathrm{mg} / \mathrm{kg}$; Fig. 4A,B). A Drug $\times$ Dose $\times$ Day ANOVA conducted on the intake of the CS + during the acquisition phase of the experiment revealed a significant 3-way interaction $\left(F_{(9,174)}=3.23, P<0.01\right)$. Post-hoc analyses indicated that IC-Nic, relative to IC-Veh, rats drank significantly more saccharin on days 3 and 4 of conditioning with $5.0 \mathrm{mg} / \mathrm{kg}$ morphine and on days 2, 3, and 4 of conditioning with both 10 and $20 \mathrm{mg} / \mathrm{kg}$ morphine. 
A

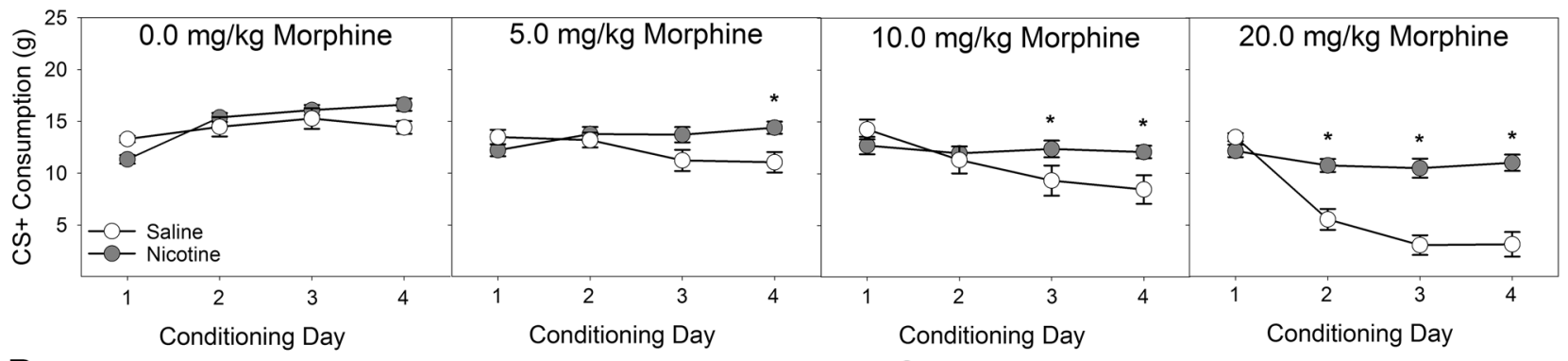

B

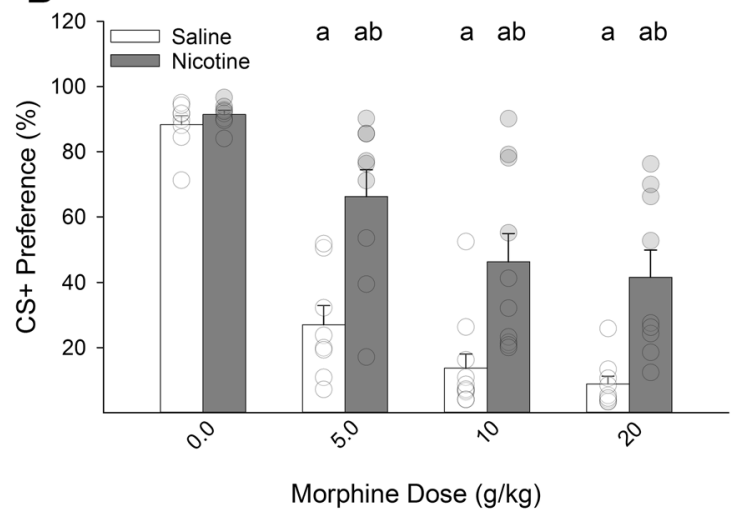

C

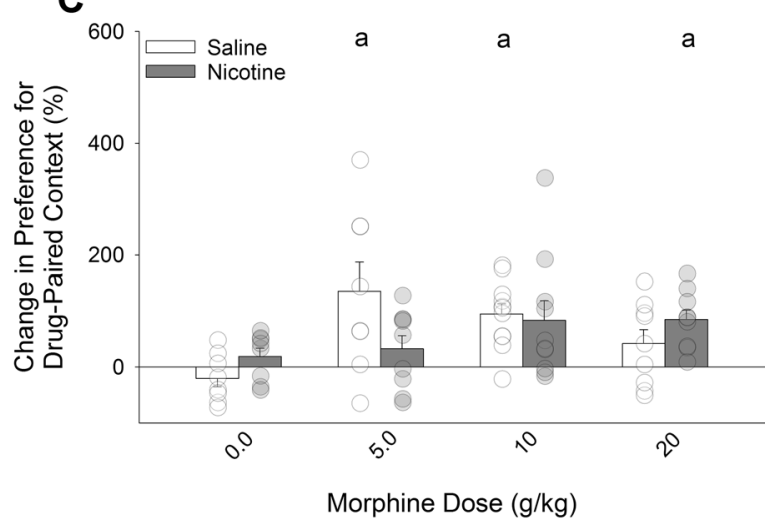

D

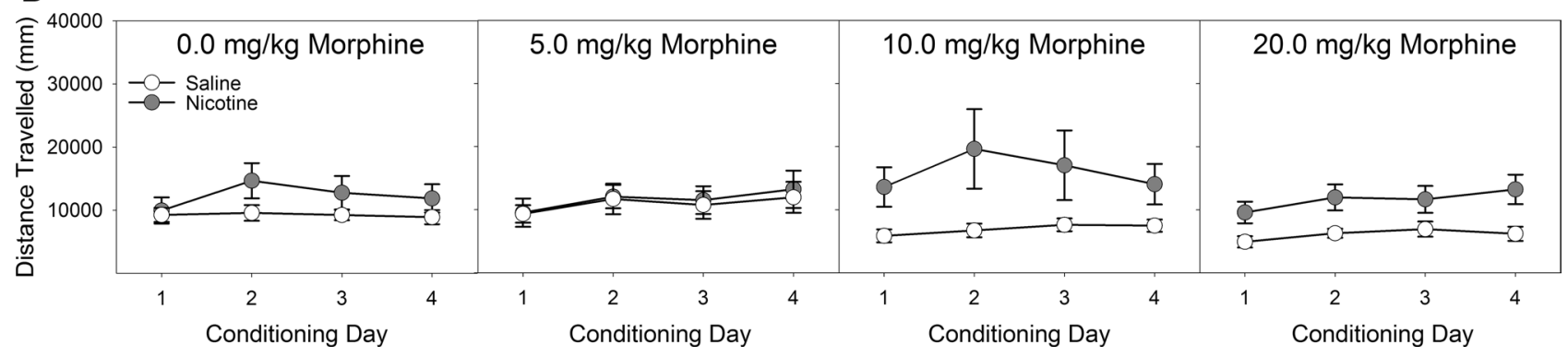

Figure 2. Systemic nicotine injections shift the dose-response curve of morphine-induced conditioned taste avoidance and place preference rightward. (A) Systemic pretreatment with $0.4 \mathrm{mg} / \mathrm{kg}$ of nicotine reduced the acquisition of CTA induced by three doses of morphine relative to saline pretreatment. (B) Similarly, previously nicotine-treated rats expressed a reduced CTA to saccharin following pairing with three doses of morphine. At each dose of morphine, previously nicotine-treated rats displayed significantly greater preference for the saccharin CS relative to saline-treated rats. These differences were observed in 24 -h two-bottle preference tests in the absence of fluid restriction and ongoing nicotine administration. (C) Nicotine pretreatment similarly shifted the dose-response function in the CPP paradigm such that the lowest dose of morphine tested (5 mg/ $\mathrm{kg}$ ) failed to produce a significant place preference in nicotine-treated rats while sufficiently producing a place preference in saline-treated rats. At the highest dose of morphine $(20 \mathrm{mg} / \mathrm{kg})$, saline-treated rats failed to display a significant CPP, while nicotine-treated rats did. (D) There were no main or interactive effects of nicotine on the locomotion during conditioning with morphine. a's indicate significant differences between conditioned rats and their unconditioned controls $(P s<0.05)$ and *'s and b's indicate significant nicotine and vehicle group differences $(P s<0.05)$.

Analyses of the expression test confirmed the effects observed during the acquisition phase in that IC-Nic rats failed to express a morphine-induced CTA at any dose tested, while IC-Veh rats expressed a dose-dependent decrease in the preference for saccharin over water (Fig. 4B). A Drug $\times$ Dose ANOVA conducted on the preference for the $\mathrm{CS}+$ in the absence of any further drug administrations revealed a significant 2 -way interaction $\left(F_{(3,58)}=3.59, P<0.05\right)$. Post-hoc analyses determined that, compared to unconditioned controls, IC-Veh rats expressed a CTA at all three doses of morphine while IC-Nic rats did not differ from their unconditioned controls at any dose. In addition, saline-treated rats displayed a significantly lower preference relative to nicotine-treated rats following conditioning with $20 \mathrm{mg} / \mathrm{kg}$ morphine, the difference following conditioning with $10 \mathrm{mg} / \mathrm{kg} \mathrm{mor-}$ phine failed to survive Bonferroni correction. There was no effect of nicotine on the preference for saccharin in the unconditioned controls. 


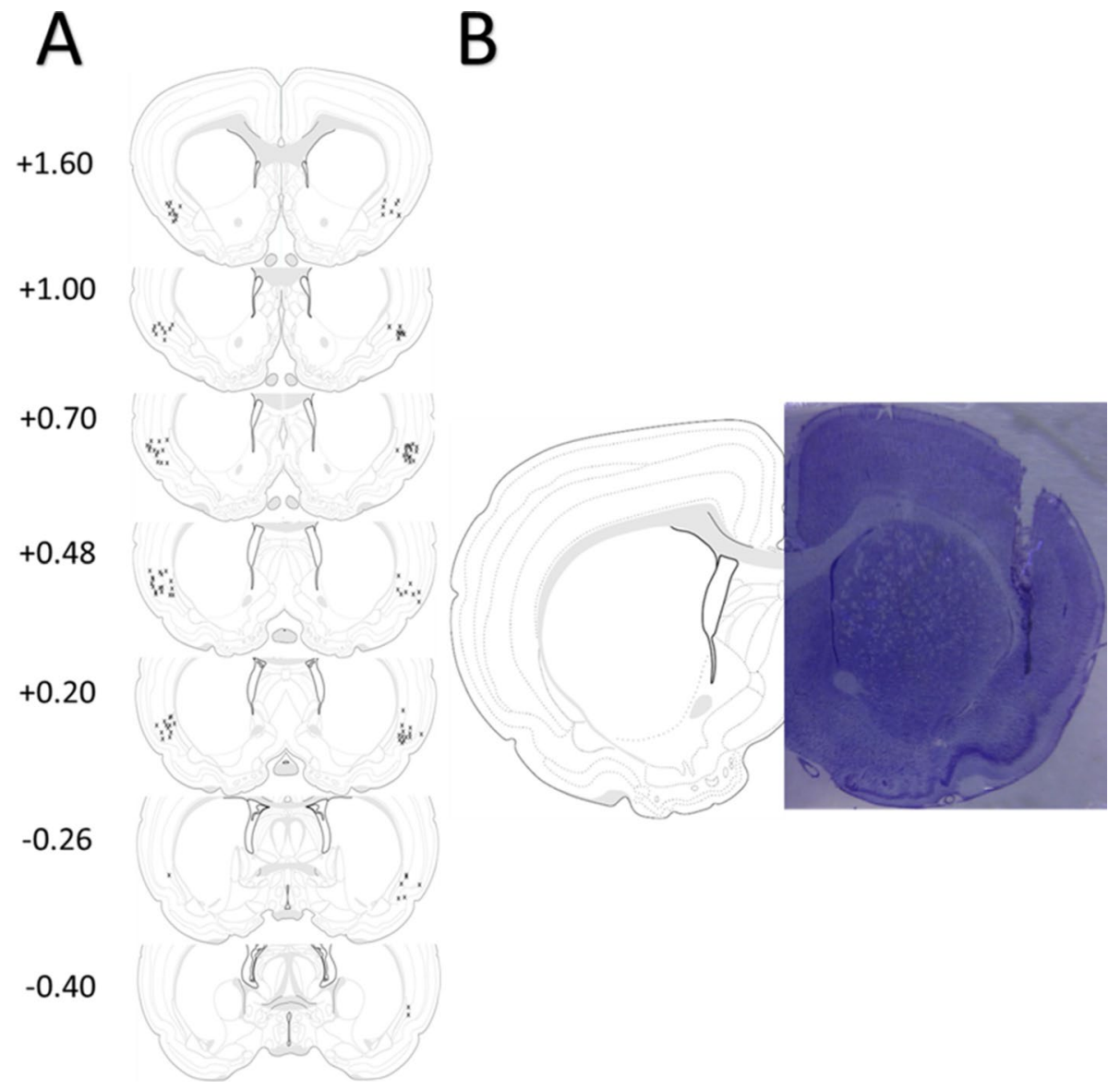

Figure 3. Location of injection sites within the insular cortex. (A) Coronal plates adapted from ${ }^{80}$ depicting approximate injection sites and their distance from bregma from all rats included in Experiment 2. (B) Representative thionin-stained coronal section depicting the cannulae track targeting the insular cortex.

Conditioned place preference. Insular infusion of nicotine significantly altered the pattern of expression of CPP following conditioning with multiple doses of morphine (Fig. 4C). A Drug $\times$ Dose ANOVA conducted on the change score in preference for the drug-paired floor context following conditioning with each dose of morphine revealed a significant 2 -way interaction $\left(F_{(3,59)}=3.30, P<0.05\right)$. Post-hoc analyses indicated that, while IC-Nic rats failed to show a reliable CPP following conditioning with $5.0 \mathrm{mg} / \mathrm{kg}$ morphine, they did show a significant CPP following conditioning with $10 \mathrm{mg} / \mathrm{kg}$ morphine, where vehicle-treated rats did not $(P<0.05)$, indicative of a rightward-ward shift in the sensitivity to morphine in the place conditioning procedures. Peak CPP in IC-Veh rats was observed following conditioning with $5.0 \mathrm{mg} / \mathrm{kg}$ morphine, relative to unconditioned controls, while peak CPP in IC-Nic rats was observed following conditioning with $10 \mathrm{mg} / \mathrm{kg}$ morphine. There were no main or interactive effects of nicotine on the locomotor response during conditioning with morphine (Fig. 4D).

\section{Discussion}

Within the present set of experiments, we demonstrate that nicotine pretreatment significantly impacts both the operant self-administration of remifentanil and morphine (Fig. 1) as well as the formation of memories associated with the aversive (Figs. 2A, 4A) and rewarding (Figs. 2B, 4B) properties of passively-administered morphine. While previous reports have indicated that systemic nicotine can impact the formation of drugassociated memories ${ }^{12,22,31}$ we have replicated those findings here and further demonstrated that nicotine, acting solely within the IC, is sufficient to produce a similar rightward shift in the dose-response curve in conditioning paradigms with morphine implicating the IC as an important locus of action for nicotine-induced modulation of drug-associated memories.

Systemic nicotine administration enhances the self-administration of multiple classes of commonly abused drugs in rodent models ${ }^{20,52,53}$. Surprisingly, there has been remarkably little work on nicotine facilitation of opioid self-administration in preclinical models despite the abundance of evidence in humans that concurrent nicotine use is strongly associated with development of OUDs ${ }^{2,5,6}$ and directly enhances consumption of methadone ${ }^{14}$. Here, we found that systemic pretreatment with nicotine $(0.4 \mathrm{mg} / \mathrm{kg})$, compared to saline, markedly enhanced intake of the ultra-short-acting synthetic opioid remifentanil, doubling the amount of remifentanil self-administered across a two-hour session (131.91 \pm 11.24 vs $279.82 \pm 28.79 \mu \mathrm{g} / \mathrm{kg})$. Given the rapid metabolism of remifentanil and resultant short duration of its effects, we chose to examine the enhancement effects of nicotine on a longer lasting opioid in morphine. Similarly, nicotine pretreatment enhanced intake of morphine 
A

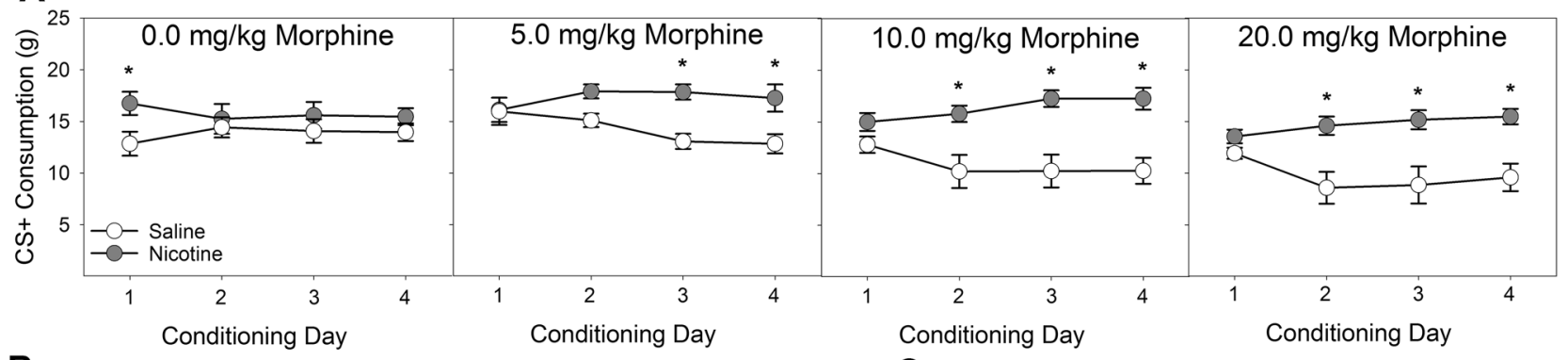

B

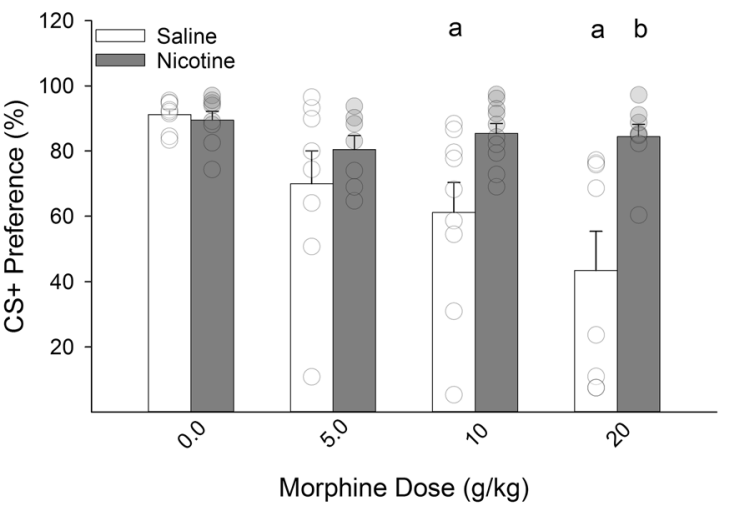

C

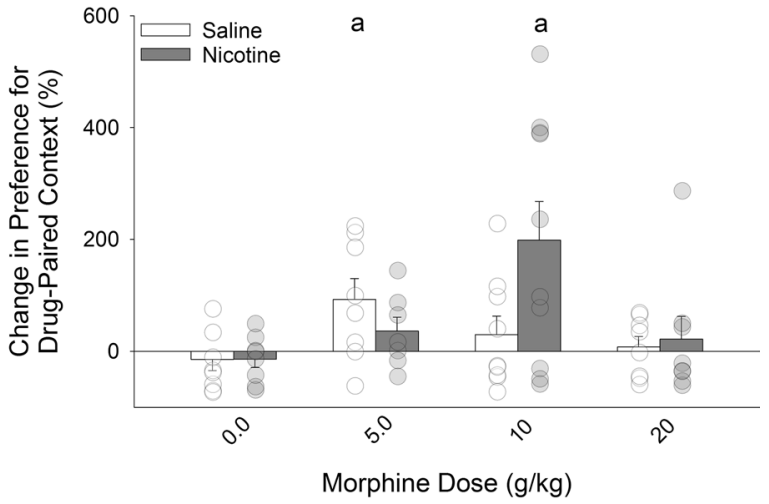

D

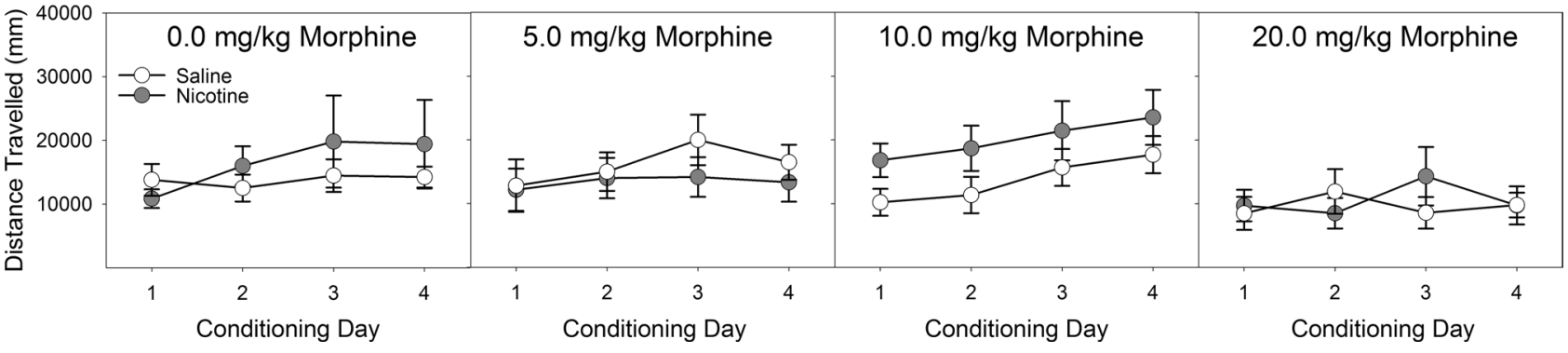

Figure 4. Intra-Insular nicotine infusions, similar to systemic nicotine injections, shift the dose-response curve for the acquisition of morphine-induced conditioned taste avoidance and place preference rightward. (A) Pretreatment with $4 \mu \mathrm{g}$ of nicotine into the insular cortex blocked the acquisition of CTA induced by three doses of morphine relative to vehicle pretreatment. (B) Similarly, previously nicotine-treated rats failed to express a CTA to saccharin following pairing with any of three doses of morphine. Furthermore, at the highest dose of morphine $(20 \mathrm{mg} / \mathrm{kg})$, previously nicotine-treated rats displayed significantly greater preference for the saccharin CS relative to saline-treated rats. These differences were observed in 24 -h two-bottle preference tests in the absence of fluid restriction and ongoing nicotine administration. (C) Intra-insular nicotine pretreatment similarly shifted the dose-response function in the CPP paradigm such that the lowest dose of morphine tested $(5 \mathrm{mg} / \mathrm{kg})$ failed to produce a significant place preference in nicotine-treated rats while sufficiently producing a place preference in saline-treated rats. At the $10 \mathrm{mg} / \mathrm{kg}$ dose of morphine saline-treated rats failed to display a significant CPP while nicotine-treated rats did. (D) There were no main or interactive effects of intra-insular nicotine on the locomotion during conditioning with morphine. a's indicate significant differences between conditioned rats and their unconditioned controls $(P \mathrm{~s}<0.05)$ and *'s and b's indicate significant nicotine and vehicle group differences $(P \mathrm{~s}<0.05)$.

( $4.63 \pm 0.79$ vs $7.13 \pm 1.24 \mathrm{mg} / \mathrm{kg}$ ) indicating that the enhancement by nicotine was not entirely dependent on the short duration of remifentanil. These data are consistent with findings that concurrent nicotine use increases the propensity to misuse prescribed opioid medication ${ }^{6,54}$. Undoubtedly, there are likely multiple mechanisms, presumably acting in concert, through which nicotine may enhance opiate self-administration. For instance, nicotine can enhance the incentive salience of discrete drug-associated cues ${ }^{19,24,25}$ and therefore increase the likelihood of drug intake upon presentation of said cues. In addition, nicotine can enhance dopamine dynamics in response to subsequently presented drugs ${ }^{55}$, including disinhibition of dopamine release from the VTA ${ }^{56}$, which presumably would increase the reinforcing efficacy of any subsequently administered drug. As such, nicotine pretreatment can alter the response to subsequent drugs of abuse through myriad mechanisms all independently contributing to the enhanced SUD liability observed in habitual users of nicotine-containing products ${ }^{1-5}$. 
One potentially novel mechanism for enhanced SUD liability resultant from concurrent nicotine use is that nicotine may promote insular dysfunction by limiting excitatory synaptic plasticity within the IC through the activation of $n$ AchRs on GABAergic interneurons ${ }^{47-49}$. Bath application of nicotine to insular slices in vitro facilitates GABAergic transmission and ultimately results in long-term depression (LTD) at pyramidal synapses. The IC is critically involved in the processing and integration of the interoceptive properties of drugs of abuse as well as the formation of drug-associated memories ${ }^{40,44-46,57-60}$. Furthermore, IC dysfunction underlies many of the maladaptive decision processes that are characteristic of SUDs, including continued drug use despite adverse consequences, and is critically associated with various forms of relapse ${ }^{61-63}$. In addition, the IC appears to be critical for maintenance of nicotine self-administration ${ }^{38,41,51}$. Here, we demonstrate for the first time that local IC application of nicotine in vivo significantly impacts the formation of contextual memories associated with the aversive and reinforcing properties of opiates as would be predicted from in vitro slice preparations ${ }^{47}$. Detrimental effects of nicotine pretreatment on contextual conditioning have been demonstrated previously, both directly and indirectly, across multiple paradigms ${ }^{11,31,64-66}$. For instance, acute nicotine pretreatment in the ventral hippocampus impairs contextual fear conditioning ${ }^{65}$ without affecting acute freezing signaled by a discrete cue $^{66}$. Additionally, adolescent exposure to nicotine impairs learning in adulthood about contexts associated with foot-shock, but has no effect on learning that a discrete cue predicts foot-shock ${ }^{64}$. Adolescent exposure to nicotine similarly impairs aversive taste conditioning induced by alcohol later in adulthood ${ }^{22}$. Moreover, the context associated with nicotine self-administration is not sufficient to maintain high-levels of nicotine selfadministration in the absence of discrete cues suggesting that nicotine administration may particularly promote the salience of discrete cues at the expense of contextual information ${ }^{67,68}$.

In the present study we examined the effects of both systemic $(0.4 \mathrm{mg} / \mathrm{kg})$ and intra-insular $(4 \mu \mathrm{g})$ pretreatment with nicotine on a combined CTA/CPP paradigm in which we measured the strength of both place and taste conditioning in the same animal following four passive administrations of morphine. We tested multiple doses of morphine $(5.0,10$, and $20 \mathrm{mg} / \mathrm{kg}$ ) across individual groups of rats and found that administration of nicotine, relative to vehicle, interfered with the acquisition of CTA to all doses of morphine tested. This response was observed during the acquisition phase of the experiment when the animals were water deprived (Figs. 2A, $4 \mathrm{~A}$ ) and actively receiving nicotine infusions, and also in the expression phase in which the animals had 24-h access to fluid and were no longer receiving nicotine administrations (Figs. 2B, 4B). These results indicate that the effects were not due to any ability for nicotine to induce hyperphagia of the saccharin solution or that nicotine was somehow interacting with deprivation state to influence greater fluid consumption. Similarly, we found that that both forms of nicotine administration impacted morphine CPP in manner that indicated a similar rightward shift in the dose-response curve. Consistent with previous studies ${ }^{11,30}$, we show that systemic nicotine administration blocked the CPP observed following conditioning with a low dose of morphine $(5.0 \mathrm{mg} / \mathrm{kg})$, and this was also observed following intra-insular nicotine pretreatment. Higher doses of morphine that failed to condition a significant CPP in saline-treated rats, produced a significant CPP following both systemic and intra-insular nicotine administration (20 and $10 \mathrm{mg} / \mathrm{kg}$, respectively).

Nicotine treatment shifted the dose response curve for morphine in both CTA and CPP paradigms rightward indicative of decreased sensitivity to the effects of morphine in these specific paradigms. Consistent with our previous findings ${ }^{12}$, nicotine did not result in an inability to form these associations, but rather interfered with the strength of conditioning, and these effects closely mimic those observed following IC lesions and pharmacological inactivation ${ }^{40,44,46}$ as well as intracerebroventricular nicotine administration ${ }^{30}$. In agreement with these previous studies, comparisons of the data from experiments 2 and 3 suggest that the animals with insular cannulae in experiment 3 , regardless of pretreatment condition, appeared to be less sensitive to the properties of morphine in both of the contextual conditioning paradigms (CTA and CPP) relative to the intact animals of experiment 2. Given that implantation of the bilateral guide cannulae and infusions undoubtedly produced some damage to insular tissue, this observation is consistent with previous lesion studies. Regardless, across both experiments, nicotine produced similar effects following both routes of administration, compared to vehicle administration. Given that systemic nicotine would invariably be acting across numerous brain areas, the finding that the pattern of results between systemic and intra-insular administration were similar suggests that IC is an important area for the effects of nicotine on drug-associated contextual conditioning. It would be important to determine in future studies the relative involvement of additional brain areas associated with these forms of conditioning (e.g. VTA, hippocampus, amygdala etc. ${ }^{69}$ ) as well as blocking insular nAChRs following systemic nicotine administration to determine the necessity of IC nAChRs to the present findings.

The present pattern of results reveals two important considerations. The first is that CTA and CPP conditioning are, in fact, dissociable. For instance, we found that IC nicotine administration blocked CTA to a given dose of morphine $(10 \mathrm{mg} / \mathrm{kg})$ while simultaneously enhancing CPP to that same dose. Given our findings and those of others ${ }^{70}$, it follows that CTA and CPP are conditioned by differing interoceptive properties of morphine. It should be noted that while we did not find a systematic relationship between the strength or type (i.e. aversive or reinforcing) of conditioning between the two paradigms used here, both CTA and CPP paradigms may differ in their relative sensitivity to conditioning with the various interoceptive properties of drugs of abuse like morphine. The second consideration is that nicotine-treated animals were not incapable of forming opiate-associated memories; rather they required higher doses of morphine to do so. This is consistent with our previous work on systemic nicotine and morphine-CTA ${ }^{12}$ wherein systemically-treated nicotine rats could learn to avoid a taste stimulus paired with morphine administration but they needed a substantially larger dose in order to do so comparably to saline-treated rats. Importantly, nicotine administration does not completely abolish all forms of insular-dependent associative learning; nicotine-treated rats competently learn a taste aversion to the visceral malaise-inducing compound lithium chloride ${ }^{21}$ which has no known reinforcing value. This raises the intriguing possibility that through putatively enhancing insular inactivation, nicotine may be reducing the perception of the unconditioned interoceptive properties of subsequent drug administration in a manner that facilitates larger, 
and potentially more frequent, doses. In agreement, human smokers are less sensitive to the analgesic properties of opiates ${ }^{54}$ requiring higher and more frequent doses. In addition, nicotine impacts interoceptive detection of cocaine in humans such that pretreatment with nicotine necessitates longer periods and stronger doses in order to report the passive administration of cocaine ${ }^{71}$, relative to placebo. In paradigms examining the interoceptive impact of combined nicotine and alcohol administration, nicotine is found to be the more salient interoceptive $\mathrm{cue}^{72}$. Furthermore, insular manipulations in rats interfere with processing the interoceptive effects of alcohol ${ }^{73,74}$. While our findings are not inconsistent with such an interpretation, the present studies were primarily concerned with the effects of nicotine on opioid self-administration and the formation of drug-associated memories and therefore more work is required to determine if insular nicotinic activity results in acute decrements in drug detection and these studies are currently being conducted.

These current studies are not without their limitations. For instance, all of these studies were conducted in male rats. In a previous report ${ }^{12}$, we demonstrated that systemic nicotine impaired the acquisition of ethanol CTA in both males and females, and the effect appeared to be larger in female rats. It remains to be determined if the IC similarly contributes to this effect in females. Additionally, while these forms of site-specific behavioral pharmacological approaches can yield insight into the relative involvement of a brain area towards a phenomenon, they are limited in their specificity of various sub-regions of the structure in question. Specifically, it is certain that in this, and other experimental approaches, the drug infusions spread throughout the brain area and so we cannot make claims as to the contribution of insular subregions (i.e. granular, dysgranular, or agranular) to the present results. Additionally, it would be informative to include a separate brain area in order to serve as a negative control thus demonstrating the specific role of nAChRs within the insular cortex. As such, future studies using these behavioral paradigms and employing circuit specific viral approaches ${ }^{75}$ are warranted. Finally, though the combined CTA/CPP approach is powerful in determining the strength of approach and avoidance inclinations in a given animal at a given dose of drug, there is some room for interactive effects between the two conditioning paradigms. For instance, it is possible the availability of saccharin could serve as an occasion setter and thus influence the strength of subsequent conditioning in the CPP context. It would be informative to determine if the present results hold if both paradigms are used independently. In support of such an assumption, we have previously demonstrated that systemic nicotine pretreatment similarly impairs CTA acquisition in the absence of CPP conditioning ${ }^{21}$ and others have shown identical effects of systemic and intracerebroventricular nicotine in CPP paradigms, at least following conditioning with $5.0 \mathrm{mg} / \mathrm{kg}$ morphine, in the absence of antecedent saccharin CTA ${ }^{11,30}$.

In summary, we report that acute nicotine administration significantly enhances the self-administration of remifentanil and morphine. In addition, acute nicotine administered either systemically or directly to the IC modulates the formation of drug-associated memories in a manner that indicates that nicotine-treated rats require higher doses in order to form comparable contextual drug associations relative to controls. These data not only emphasize the importance of nicotine co-use in the development and maintenance of problematic drug use but also further our understanding of the importance of the insular cortex in nicotine-facilitated polysubstance use.

\section{Methods and materials}

Animals and housing. 161 adult male Long-Evans rats weighing approximately $350 \mathrm{~g}$ (Envigo; Indianapolis, IN) were individually housed on a reverse light cycle in polycarbonate cages in a humidity- and temperature-controlled vivarium. Following arrival to the facilities, rats were handled daily for three days and given at least one week to acclimate prior to the start of the experiments. Two rats were excluded from experiment 2 due to development of illness and one rat died before completion of the study. Eleven rats were eventually excluded from Experiment 2 due to either misplaced cannulae or the development of illness. All procedures were approved by the University at Buffalo Institutional Animal Care and Use Committee and were carried out in accordance with all relevant guidelines and regulations including applicable Animal Research: Reporting of In Vivo Experiments (ARRIVE) guidelines.

Chemical stimuli. Nicotine hydrogen tartrate salt (Glentham Life Sciences; U.K.) was dissolved in phosphate buffered saline (PBS; pH 7.2-7.4). All nicotine doses are expressed as the freebase. Morphine sulfate (Spectrum Chemicals; New Brunswick, NJ) was dissolved in saline. Remifentanil hydrochloride (NIDA drug supply program) was dissolved in saline. Saccharin sodium (Sigma-Aldrich; St Louis, MO) was dissolved in tap water.

Experiment 1: does systemic nicotine administration enhance intravenous morphine self-administration? Surgical procedures. Rats $(n=9)$ were surgically implanted with chronically indwelling catheters in the right jugular vein under isoflurane anesthesia (1-3\%). Briefly, a $15 \mathrm{~cm}$ catheter line (C30PURJV1402, Instech) was implanted into the right external jugular vein and the other end was connected to an externalized vascular access button (VABR1B/22, Instech). Each access button was implanted just posterior to the scapular region on the dorsal side of the rat. Catheters were flushed with $0.1 \mathrm{~mL}$ of heparinized saline and enrofloxacin (Baytril, Bayer HealthCare LLC; Shawnee Mission, KS) before and after self-administration on test days. Catheter patency was verified at the conclusion of the study by flushing $0.1 \mathrm{ml}$ of ketamine $(10 \mathrm{mg} / \mathrm{ml})$ and verifying the expression of ataxia.

Behavioral procedures: intravenous self-administration. Rats were trained to press a lever in standard operant boxes (Med Associates; St Albans, VT) for delivery of a drug reinforcer in two-hour sessions. Behavior was shaped such that one press of the active-lever resulted in intravenous delivery of remifentanil $(3.2 \mu \mathrm{g} /$ $\mathrm{kg}$ ) while presses of the inactive-lever had no consequence. Once stable responding was established (7 days), 
rats were advanced to an FR-3 schedule of reinforcement. Once stable responding was confirmed on FR-3, rats were given two, non-contingent sub cutaneous (s.c.) injections of nicotine $(0.4 \mathrm{mg} / \mathrm{kg})$ across two days in their homecage, in the absence of operant test sessions, in order to familiarize them to the effects of nicotine. Next, rats were tested for FR-3 responding for remifentanil in two sessions, once each under the effects of nicotine pretreatment $(0.4 \mathrm{mg} / \mathrm{kg}$ s.c., $15 \mathrm{~min}$ before session start) or saline $(1.0 \mathrm{ml} / \mathrm{kg}$ s.c., $15 \mathrm{~min}$ before session start). One week following the last FR-3 session with remifentanil, rats were placed back into the operant chambers and now allowed to self-administer morphine $(0.3 \mathrm{mg} / \mathrm{kg})$ on an FR-3 schedule. Once stable responding for morphine was confirmed the rats were similarly tested for FR-3 morphine responding following nicotine $(0.4 \mathrm{mg} / \mathrm{kg})$ and saline pretreatment. Location of the active and inactive lever and order of testing (nicotine or saline) were counter-balanced across all rats.

Experiment 2: does systemic nicotine alter contextual conditioning with the interoceptive effects of morphine? Behavioral procedures: combined CTA/CPP paradigm. Rats $(\mathrm{n}=72)$ were maintained on a $23 \mathrm{~h}$ water deprivation schedule and tested in a combined CTA/CPP paradigm (see timeline; Fig. 5A). The behavioral paradigm consisted of 4 distinct phases. In order of presentation, they were: drug pretreatment (nicotine/saline); fluid access (saccharin/water); US administration (0.0,5.0,10, $20 \mathrm{mg} / \mathrm{kg}$ morphine); place conditioning. Briefly, rats were trained to consume fluid during a 30 min session until intakes stabilized ( $\sim 5-7$ days). On the last training day, immediately following the fluid-access period, rats were placed in the CPP apparatus and their baseline preference for the two contexts was assessed. We employed a biased CPP procedure where the least preferred floor from the baseline assessment was assigned as the CS+ condition and the most preferred floor as the CS- condition. Immediately following training, rats were assigned to an experimental condition in a counter-balanced fashion.

During testing, rats were first injected subcutaneously with either $0.4 \mathrm{mg} / \mathrm{kg}$ nicotine or saline. Following injections, rats were returned to their homecage for $30 \mathrm{~min}$. Next. They were given access to fluid (saccharin or water) for $30 \mathrm{~min}$ in their homecage. As such, nicotine was administered $60 \mathrm{~min}$ prior to the unconditioned stimulus (US) in both conditioning paradigms (CTA/CPP); a time-course consistent with previous nicotine pre-treatment studies ${ }^{23,76}$ and the known bioavailability of nicotine ${ }^{77-79}$. Following the fluid-access period, rats were removed from their homecage and injected with either saline or morphine $(5.0,10$, or $20 \mathrm{mg} / \mathrm{kg}$, s.c.) and placed into the CPP apparatus equipped with the appropriate floor context for $30 \mathrm{~min}$. This resulted in a total of 8 experimental groups: three doses of morphine following systemic nicotine and the same three doses following saline and their respective unconditioned controls.

On CS- days, all rats were given access to water for $30 \mathrm{~min}$ immediately followed by an injection of saline prior to transfer to the CPP chambers. On CS+ days, all rats were given access to $0.1 \%$ saccharin for $30 \mathrm{~min}$ and immediately injected with their assigned morphine dose prior to transfer to the CPP chambers (see Fig. 5a). Conditioning lasted for a total of 8 days in which CS- and CS+ conditions were alternated for a total of four taste-context-drug pairings.

Following conditioning, the strength of the place preference was first assessed by placing the rats in the CPP apparatus equipped with both floor contexts in the absence of any drug administrations. Rats were left for $30 \mathrm{~min}$ and the amount of time spent in either context was measured. One day after CPP expression tests, the strength of CTA was assessed by giving rats $24 \mathrm{~h}$ access to two fluid bottles in their homecage, one bottle contained tap water and the other contained $0.1 \%$ saccharin. Rats were free to consume from either bottle and the preference for saccharin over water was calculated. Bottle positions were counterbalanced across all experimental groups.

Experiment 3: does nicotine delivered locally to the insular cortex affect contextual interoceptive conditioning with morphine? Surgical procedures. Rats $(\mathrm{n}=78)$ were restrained in a stereotaxic apparatus (Kopf Instruments; Tujunga, CA) with non-traumatic ear bars and maintained on isoflurane (2-4\%) throughout the duration of the surgical procedure. Stainless-steel guide cannulae (26 gauge, $8.0 \mathrm{~mm}$ in length; Invivo1; Roanoke, VA) targeting $2.0 \mathrm{~mm}$ dorsal to the agranular insular cortex $(+0.5 \mathrm{~A} / \mathrm{P} ; \pm 5.7 \mathrm{M} / \mathrm{L} ;-4.4 \mathrm{D} / \mathrm{V})$ were bilaterally implanted and fixed to the skull with screws and dental cement. Dummy cannulae (36 gauge) were inserted into the guide cannulae in order to prevent occlusion. All rats were given 7 days to recover prior to the start of behavioral experiments.

Following recovery, rats were trained and tested in an identical combined CTA/CPP design as described above (Experiment 2) with a few critical changes (Fig. 5B). Each day, rats were gently restrained for approximately two minutes while dummy cannulae were removed and injectors were inserted into both cannulae. Immediately following training, rats were assigned to an experimental condition in a counter-balanced fashion. During testing, rats were first bilaterally infused into the IC with $1 \mu \mathrm{l}$ of their assigned stimulus ( $4 \mu \mathrm{g}$ nicotine; IC-Nic or vehicle; IC-Veh) at a rate of $0.5 \mu \mathrm{l} / \mathrm{min}$. Injectors (extending $2.0 \mathrm{~mm}$ beyond cannulae) were left in place for an additional minute to allow for adequate diffusion away from the injection tract. Following infusions, rats were returned to their homecage for $15 \mathrm{~min}$ before given access to fluid (saccharin or water) for $30 \mathrm{~min}$. Following the fluid-access period, rats were removed from their home cage and injected with either saline or morphine $(5.0,10$, or $20 \mathrm{mg} / \mathrm{kg}$, s.c.) and placed into the CPP apparatus equipped with the appropriate floor context for $30 \mathrm{~min}$. This resulted in a total of 8 experimental groups: three doses of morphine following IC-Veh and three doses following IC-Nic and their respective unconditioned controls. Testing lasted for 8 days (4 alternations of CS- and CS+ conditioning trials) and the strength of CTA and CPP conditioning as a function of insular-drug delivery and morphine dose $(0.0,5.0,10$, or $20 \mathrm{mg} / \mathrm{kg}$, s.c.) were assessed as described above.

Histology. Following behavioral testing, rats were anesthetized with pentobarbital and transcardially perfused with ice cold saline followed by $4 \%$ paraformaldehyde (PFA) in $0.1 \mathrm{M}$ phosphate buffer and their brains were 
A

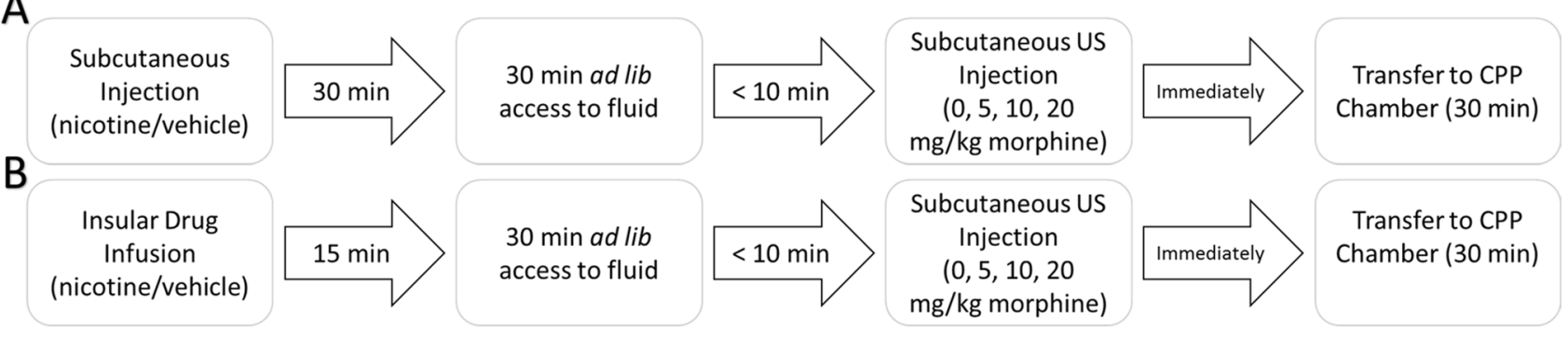

Figure 5. Experimental timeline on conditioning days. On conditioning days in Experiment 2 (A), rats were first subcutaneously injected with their assigned drug and returned to their home cage. 15 min later the rats were given access to fluid in their homecage for $30 \mathrm{~min}$. Within $10 \mathrm{~min}$ of cessation of the fluid access period, rats were injected with their assigned morphine dose (s.c.) and immediately placed into the CPP chambers for $30 \mathrm{~min}$ prior to being returned to their homecage. In Experiment 3 (B) the same protocol was followed with the exception that the animals were bilaterally infused into the insula with their assigned drug and returned to their home cage. $15 \mathrm{~min}$ later the rats were given access to fluid in their homecage and all other procedures were identically followed.

removed. Brains were post-fixed in PFA overnight. Fixed brains were cryoprotected by sinking in a $15 \% \mathrm{w} / \mathrm{v}$ buffered sucrose solution for one day followed by a 30\% sucrose solution. The insular cortex was sectioned at $40 \mu \mathrm{m}$ on a freezing microtome (Hacker Instruments; Winnsboro, SC) and sections were transferred to slides and stained with a $0.1 \%$ thionin solution. Images were obtained of the brain sections on a microscope equipped with a digital camera (Cole-Parmer; Vernon Hills, IL) and placement of injection sites within the insular cortex were verified (see Fig. 3).

Data analyses. For the IVSA portion of the experiments, the total number of active and inactive lever presses, as well as total infusions earned were independently analyzed for both remifentanil and morphine IVSA in repeated measures ANOVAs with Drug pretreatment (nicotine or saline) as within-subjects factor. Post-hoc analyses of repeated factors were conducted with Fisher's LSD.

For the CTA portion of the experiments, intake of the saccharin CS and water were analyzed independently in a mixed repeated measures ANOVA with Drug (nicotine or saline) and morphine Dose (0.0, 5.0, 10, $20 \mathrm{mg} /$ $\mathrm{kg}$ morphine) as between-subjects factors and conditioning Day as within-subjects factors. Post-hoc analyses of repeated factors was conducted with Fisher's LSD. For CTA 2-bottle expression tests, intake data were converted to a preference score (CS+ over CS-) and were analyzed with a two-factor (Drug and morphine Dose) between-subjects ANOVA. Bonferroni-corrected t-tests were used to assess strength of conditioning within- and between-groups separately.

For CPP expression tests, the percent change in preference for the drug-paired context relative to the baseline preference test was analyzed with a two-factor (Drug and US Dose) between-subjects ANOVA. Separate Bonferroni-corrected t-tests were used to assess strength of conditioning within- and between-groups. Statistical analyses were conducted in Statistica 12 software package.

Received: 30 September 2020; Accepted: 13 January 2021

Published online: 08 February 2021

\section{References}

1. Weinberger, A. H. et al. Cigarette smoking is associated with increased risk of substance use disorder relapse: A nationally representative, prospective longitudinal investigation. J. Clin. Psychiatry 78, e152-e160. https://doi.org/10.4088/JCP.15m10062 (2017).

2. Nahvi, S., Richter, K., Li, X., Modali, L. \& Arnsten, J. Cigarette smoking and interest in quitting in methadone maintenance patients. Addict. Behav. 31, 2127-2134. https://doi.org/10.1016/j.addbeh.2006.01.006 (2006).

3. Kohut, S. J. Interactions between nicotine and drugs of abuse: A review of preclinical findings. Am. J. Drug Alcohol Abuse 43, 155-170. https://doi.org/10.1080/00952990.2016.1209513 (2017).

4. Tuesta, L. M., Fowler, C. D. \& Kenny, P. J. Recent advances in understanding nicotinic receptor signaling mechanisms that regulate drug self-administration behavior. Biochem. Pharmacol. 82, 984-995. https://doi.org/10.1016/j.bcp.2011.06.026 (2011).

5. Frosch, D. L., Shoptaw, S., Nahom, D. \& Jarvik, M. E. Associations between tobacco smoking and illicit drug use among methadonemaintained opiate-dependent individuals. Exp. Clin. Psychopharm. 8, 97-103. https://doi.org/10.1037/1064-1297.8.1.97 (2000).

6. Zale, E. L. et al. Tobacco smoking, nicotine dependence, and patterns of prescription opioid misuse: Results from a nationally representative sample. Nicotine Tob. Res. 17, 1096-1103. https://doi.org/10.1093/ntr/ntu227 (2015).

7. Yoon, J. H., Lane, S. D. \& Weaver, M. F. Opioid analgesics and nicotine: More than blowing smoke. J. Pain Palliat. Care Pharmacother. 29, 281-289. https://doi.org/10.3109/15360288.2015.1063559 (2015).

8. Skurtveit, S., Furu, K., Selmer, R., Handal, M. \& Tverdal, A. Nicotine dependence predicts repeated use of prescribed opioids, prospective population-based cohort study. Ann. Epidemiol. 20, 890-897. https://doi.org/10.1016/j.annepidem.2010.03.010 (2010).

9. Henningfield, J. E., Clayton, R. \& Pollin, W. Involvement of tobacco in alcoholism and illicit drug-use. Br. J. Addict. 85, 279-292 (1990).

10. Feng, B. et al. Blocking alpha4beta2 and alpha7 nicotinic acetylcholine receptors inhibits the reinstatement of morphine-induced CPP by drug priming in mice. Behav. Brain Res. 220, 100-105. https://doi.org/10.1016/j.bbr.2011.01.040 (2011).

11. Zarrindast, M. R., Faraji, N., Rostami, P., Sahraei, H. \& Ghoshouni, H. Cross-tolerance between morphine- and nicotine-induced conditioned place preference in mice. Pharmacol. Biochem. Behav. 74, 363-369 (2003). 
12. Loney, G. C. \& Meyer, P. J. Nicotine pre-treatment reduces sensitivity to the interoceptive stimulus effects of commonly abused drugs as assessed with taste conditioning paradigms. Drug Alcohol Depend. 194, 341-350. https://doi.org/10.1016/j.drugalcdep .2018.07.048 (2019).

13. Glick, S. D., Ramirez, R. L., Livi, J. M. \& Maisonneuve, I. M. 18-Methoxycoronaridine acts in the medial habenula and/or interpeduncular nucleus to decrease morphine self-administration in rats. Eur. J. Pharmacol. 537, 94-98. https://doi.org/10.1016/j.ejpha r.2006.03.045 (2006).

14. Spiga, R., Schmitz, J. \& Day, J. Effects of nicotine on methadone self-administration in humans. Drug Alcohol Depend. 50, 157-165 (1998).

15. Crombag, H. S., Bossert, J. M., Koya, E. \& Shaham, Y. Review Context-induced relapse to drug seeking: A review. Philos. Trans. R. Soc. Lond. B 363, 3233-3243. https://doi.org/10.1098/rstb.2008.0090 (2008).

16. McHugh, R. K. et al. Assessing craving and its relationship to subsequent prescription opioid use among treatment-seeking prescription opioid dependent patients. Drug Alcohol Depend. 145, 121-126. https://doi.org/10.1016/j.drugalcdep.2014.10.002 (2014).

17. Krasnova, I. N. et al. Incubation of methamphetamine and palatable food craving after punishment-induced abstinence. Neuropsychopharmacology 39, 2008-2016. https://doi.org/10.1038/npp.2014.50 (2014).

18. Venniro, M., Caprioli, D. \& Shaham, Y. Animal models of drug relapse and craving: From drug priming-induced reinstatement to incubation of craving after voluntary abstinence. Prog Brain Res 224, 25-52. https://doi.org/10.1016/bs.pbr.2015.08.004 (2016).

19. Loney, G. C., Angelyn, H., Cleary, L. M. \& Meyer, P. J. Nicotine produces a high-approach, low-avoidance phenotype in response to alcohol-associated cues in male rats. Alcohol. Clin. Exp. Res. 43, 1284-1295. https://doi.org/10.1111/acer.14043 (2019).

20. Bechtholt, A. J. \& Mark, G. P. Enhancement of cocaine-seeking behavior by repeated nicotine exposure in rats. Psychopharmacology 162, 178-185. https://doi.org/10.1007/s00213-002-1079-1 (2002).

21. Loney, G. C. \& Meyer, P. J. Nicotine reduces the sensitivity to the interoceptive properties of commonly abused drugs as assessed with taste conditioning paradigms. Drug Alcohol Depend. 194, 341 (2018).

22. Rinker, J. A. et al. Exposure to nicotine during periadolescence or early adulthood alters aversive and physiological effects induced by ethanol. Pharmacol. Biochem. Behav. 99, 7-16. https://doi.org/10.1016/j.pbb.2011.03.009 (2011).

23. Kunin, D., Smith, B. R. \& Amit, Z. Nicotine and ethanol interaction on conditioned taste aversions induced by both drugs. Pharmacol. Biochem. Behav. 62, 215-221 (1999).

24. Maddux, J. N. \& Chaudhri, N. Nicotine-induced enhancement of Pavlovian alcohol-seeking behavior in rats. Psychopharmacology 234, 727-738. https://doi.org/10.1007/s00213-016-4508-2 (2017).

25. Stringfield, S. J., Boettiger, C. A. \& Robinson, D. L. Nicotine-enhanced Pavlovian conditioned approach is resistant to omission of expected outcome. Behav. Brain Res. 343, 16-20. https://doi.org/10.1016/j.bbr.2018.01.023 (2018).

26. Bevins, R. A. \& Palmatier, M. I. Extending the role of associative learning processes in nicotine addiction. Behav. Cogn. Neurosci. Rev. 3, 143-158. https://doi.org/10.1177/1534582304272005 (2004).

27. Palmatier, M. I., Kellicut, M. R., Brianna Sheppard, A., Brown, R. W. \& Robinson, D. L. The incentive amplifying effects of nicotine are reduced by selective and non-selective dopamine antagonists in rats. Pharmacol. Biochem. Behav. 126, 50-62. https://doi. org/10.1016/j.pbb.2014.08.012 (2014).

28. Nunes, E. J. et al. Cholinergic receptor blockade in the VTA attenuates Cue-induced cocaine-seeking and reverses the anxiogenic effects of forced abstinence. Neuroscience 413, 252-263. https://doi.org/10.1016/j.neuroscience.2019.06.028 (2019).

29. Singh, P. K. \& Lutfy, K. Nicotine pretreatment reduced cocaine-induced CPP and its reinstatement in a sex- and dose-related manner in adult C57BL/6J mice. Pharmacol. Biochem. Behav. 159, 84-89. https://doi.org/10.1016/j.pbb.2017.07.010 (2017).

30. Shams, J. et al. Effects of ultra-low doses of nicotine on the expression of morphine-induced conditioned place preference in mice. Behav. Pharmacol. 17, 629-635. https://doi.org/10.1097/FBP.0b013e3280102d68 (2006).

31. Araki, H. et al. Nicotine attenuates place aversion induced by naloxone in single-dose, morphine-treated rats. Psychopharmacology 171, 398-404. https://doi.org/10.1007/s00213-003-1595-7 (2004).

32. Ishida, S. et al. alpha7 Nicotinic acetylcholine receptors in the central amygdaloid nucleus alter naloxone-induced withdrawal following a single exposure to morphine. Psychopharmacology 214, 923-931. https://doi.org/10.1007/s00213-010-2101-7 (2011).

33. Ackroff, K. \& Sclafani, A. Flavor preferences conditioned by intragastric ethanol with limited access training. Pharmacol. Biochem. Behav. 75, 223-233 (2003).

34. Cunningham, C. L. \& Niehus, J. S. Flavor preference conditioning by oral self-administration of ethanol. Psychopharmacology 134, 293-302. https://doi.org/10.1007/s002130050452 (1997).

35. Loney, G. C. \& Meyer, P. J. Brief exposures to the taste of ethanol (EtOH) and quinine promote subsequent acceptance of EtOH in a paradigm that minimizes postingestive consequences. Alcohol. Clin. Exp. Res. 42, 589-602. https://doi.org/10.1111/acer.13581 (2018).

36. Pitchers, K. K., Kane, L. F., Kim, Y., Robinson, T. E. \& Sarter, M. "Hot" vs "cold” behavioural-cognitive styles: Motivationaldopaminergic vs. cognitive-cholinergic processing of a Pavlovian cocaine cue in sign- and goal-tracking rats. Eur. J. Neurosci. 46, 2768-2781. https://doi.org/10.1111/ejn.13741 (2017).

37. Gogolla, N. The insular cortex. Curr. Biol. 27, R580-R586. https://doi.org/10.1016/j.cub.2017.05.010 (2017).

38. Naqvi, N. H., Rudrauf, D., Damasio, H. \& Bechara, A. Damage to the insula disrupts addiction to cigarette smoking. Science 315, 531-534. https://doi.org/10.1126/science.1135926 (2007).

39. Naqvi, N. H., Gaznick, N., Tranel, D. \& Bechara, A. The insula: A critical neural substrate for craving and drug seeking under conflict and risk. Ann. N. Y. Acad. Sci. 1316, 53-70. https://doi.org/10.1111/nyas.12415 (2014),

40. Arguello, A. A. et al. Role of the agranular insular cortex in contextual control over cocaine-seeking behavior in rats. Psychopharmacology 234, 2431-2441. https://doi.org/10.1007/s00213-017-4632-7 (2017).

41. Forget, B., Pushparaj, A. \& Le Foll, B. Granular insular cortex inactivation as a novel therapeutic strategy for nicotine addiction. Biol. Psychiatry 68, 265-271. https://doi.org/10.1016/j.biopsych.2010.01.029 (2010).

42. Pushparaj, A. \& Le Foll, B. Involvement of the caudal granular insular cortex in alcohol self-administration in rats. Behav Brain Res 293, 203-207. https://doi.org/10.1016/j.bbr.2015.07.044 (2015).

43. Jaramillo, A. A., Van Voorhies, K., Randall, P. A. \& Besheer, J. Silencing the insular-striatal circuit decreases alcohol self-administration and increases sensitivity to alcohol. Behav. Brain Res. 348, 74-81. https://doi.org/10.1016/j.bbr.2018.04.007 (2018).

44. Geddes, R. I., Han, L., Baldwin, A. E., Norgren, R. \& Grigson, P. S. Gustatory insular cortex lesions disrupt drug-induced, but not lithium chloride-induced, suppression of conditioned stimulus intake. Behav. Neurosci. 122, 1038-1050. https://doi.org/10.1037/ a0012748 (2008).

45. Contreras, M., Ceric, F. \& Torrealba, F. Inactivation of the interoceptive insula disrupts drug craving and malaise induced by lithium. Science 318, 655-658. https://doi.org/10.1126/science.1145590 (2007).

46. Li, C. L., Zhu, N., Meng, X. L., Li, Y. H. \& Sui, N. Effects of inactivating the agranular or granular insular cortex on the acquisition of the morphine-induced conditioned place preference and naloxone-precipitated conditioned place aversion in rats. J. Psychopharmacol. 27, 837-844. https://doi.org/10.1177/0269881113492028 (2013).

47. Sato, H., Kawano, T., Yin, D. X., Kato, T. \& Toyoda, H. Nicotinic activity depresses synaptic potentiation in layer V pyramidal neurons of mouse insular cortex. Neuroscience 358, 13-27. https://doi.org/10.1016/j.neuroscience.2017.06.031 (2017).

48. Toyoda, H. Role of nicotinic acetylcholine receptors for modulation of microcircuits in the agranular insular cortex. J. Oral Biosci. 61, 5-11. https://doi.org/10.1016/j.job.2018.12.001 (2019). 
49. Toyoda, H. Nicotine facilitates synaptic depression in layer $\mathrm{V}$ pyramidal neurons of the mouse insular cortex. Neurosci. Lett. 672, 78-83. https://doi.org/10.1016/j.neulet.2018.02.046 (2018).

50. Jiang, C. et al. Morphine coordinates SST and PV interneurons in the prelimbic cortex to disinhibit pyramidal neurons and enhance reward. Mol. Psychiatry https://doi.org/10.1038/s41380-019-0480-7 (2019).

51. Hollander, J. A., Lu, Q., Cameron, M. D., Kamenecka, T. M. \& Kenny, P. J. Insular hypocretin transmission regulates nicotine reward. Proc. Natl. Acad. Sci. USA 105, 19480-19485. https://doi.org/10.1073/pnas.0808023105 (2008).

52. Cortright, J. J., Sampedro, G. R., Neugebauer, N. M. \& Vezina, P. Previous exposure to nicotine enhances the incentive motivational effects of amphetamine via nicotine-associated contextual stimuli. Neuropsychopharmacology 37, 2277-2284. https://doi. org/10.1038/npp.2012.80 (2012).

53. Le, A. D., Wang, A., Harding, S., Juzytsch, W. \& Shaham, Y. Nicotine increases alcohol self-administration and reinstates alcohol seeking in rats. Psychopharmacology 168, 216-221. https://doi.org/10.1007/s00213-002-1330-9 (2003).

54. Steinmiller, C. L. et al. Postsurgical patient-controlled opioid self-administration is greater in hospitalized abstinent smokers than nonsmokers. J. Opioid Manag. 8, 227-235. https://doi.org/10.5055/jom.2012.0120 (2012).

55. Zernig, G., O'Laughlin, I. A. \& Fibiger, H. C. Nicotine and heroin augment cocaine-induced dopamine overflow in nucleus accumbens. Eur. J. Pharmacol. 337, 1-10 (1997).

56. Mansvelder, H. D., Keath, J. R. \& McGehee, D. S. Synaptic mechanisms underlie nicotine-induced excitability of brain reward areas. Neuron 33, 905-919. https://doi.org/10.1016/s0896-6273(02)00625-6 (2002).

57. Naqvi, N. H. \& Bechara, A. The insula and drug addiction: An interoceptive view of pleasure, urges, and decision-making. Brain Struct. Funct. 214, 435-450. https://doi.org/10.1007/s00429-010-0268-7 (2010).

58. Goldstein, R. Z. et al. The neurocircuitry of impaired insight in drug addiction. Trends Cogn. Sci. 13, 372-380. https://doi. org/10.1016/j.tics.2009.06.004 (2009).

59. Moschak, T. M., Wang, X. \& Carelli, R. M. A neuronal ensemble in the rostral agranular insula tracks cocaine-induced devaluation of natural reward and predicts cocaine seeking. J. Neurosci. 38, 8463-8472. https://doi.org/10.1523/JNEUROSCI.1195-18.2018 (2018).

60. Zito, K. A., Bechara, A., Greenwood, C. \& van der Kooy, D. The dopamine innervation of the visceral cortex mediates the aversive effects of opiates. Pharmacol. Biochem. Behav. 30, 693-699 (1988).

61. Paulus, M. P., Rogalsky, C., Simmons, A., Feinstein, J. S. \& Stein, M. B. Increased activation in the right insula during risk-taking decision making is related to harm avoidance and neuroticism. Neuroimage 19, 1439-1448 (2003).

62. Stewart, J. L. et al. You are the danger: attenuated insula response in methamphetamine users during aversive interoceptive decisionmaking. Drug Alcohol Depend. 142, 110-119. https://doi.org/10.1016/j.drugalcdep.2014.06.003 (2014).

63. Stewart, J. L., Butt, M., May, A. C., Tapert, S. F. \& Paulus, M. P. Insular and cingulate attenuation during decision making is associated with future transition to stimulant use disorder. Addiction 112, 1567-1577. https://doi.org/10.1111/add.13839 (2017).

64. Spaeth, A. M., Barnet, R. C., Hunt, P. S. \& Burk, J. A. Adolescent nicotine exposure disrupts context conditioning in adulthood in rats. Pharmacol. Biochem. Behav. 96, 501-506. https://doi.org/10.1016/j.pbb.2010.07.011 (2010).

65. Kenney, J. W., Raybuck, J. D. \& Gould, T. J. Nicotinic receptors in the dorsal and ventral hippocampus differentially modulate contextual fear conditioning. Hippocampus 22, 1681-1690. https://doi.org/10.1002/hipo.22003 (2012).

66. Kutlu, M. G., Oliver, C. \& Gould, T. J. The effects of acute nicotine on contextual safety discrimination. J. Psychopharmacol. 28, 1064-1070. https://doi.org/10.1177/0269881114552743 (2014).

67. Caggiula, A. R. et al. Cue dependency of nicotine self-administration and smoking. Pharmacol. Biochem. Behav. 70, 515-530 (2001).

68. Pitchers, K. K., Phillips, K. B., Jones, J. L., Robinson, T. E. \& Sarter, M. Diverse roads to relapse: A discriminative cue signaling cocaine availability is more effective in renewing cocaine seeking in goal trackers than sign trackers and depends on basal forebrain cholinergic activity. J. Neurosci. 37, 7198-7208. https://doi.org/10.1523/JNEUROSCI.0990-17.2017 (2017).

69. Subramaniyan, M. \& Dani, J. A. Dopaminergic and cholinergic learning mechanisms in nicotine addiction. Ann. N. Y. Acad. Sci. 1349, 46-63. https://doi.org/10.1111/nyas.12871 (2015).

70. Verendeev, A. \& Riley, A. L. Relationship between the rewarding and aversive effects of morphine and amphetamine in individual subjects. Learn. Behav. 39, 399-408. https://doi.org/10.3758/s13420-011-0035-5 (2011).

71. Kouri, E. M., Stull, M. \& Lukas, S. E. Nicotine alters some of cocaine's subjective effects in the absence of physiological or pharmacokinetic changes. Pharmacol. Biochem. Behav. 69, 209-217 (2001).

72. Randall, P. A., Cannady, R. \& Besheer, J. The nicotine + alcohol interoceptive drug state: Contribution of the components and effects of varenicline in rats. Psychopharmacology 233, 3061-3074. https://doi.org/10.1007/s00213-016-4354-2 (2016).

73. Jaramillo, A. A., Randall, P. A., Frisbee, S. \& Besheer, J. Modulation of sensitivity to alcohol by cortical and thalamic brain regions. Eur. J. Neurosci. 44, 2569-2580. https://doi.org/10.1111/ejn.13374 (2016).

74. Jaramillo, A. A. et al. Functional role for suppression of the insular-striatal circuit in modulating interoceptive effects of alcohol. Addict. Biol. https://doi.org/10.1111/adb.12551 (2017).

75. Gehrlach, D. A. et al. Aversive state processing in the posterior insular cortex. Nat. Neurosci. 22, 1424-1437. https://doi.org/10.1038/ s41593-019-0469-1 (2019).

76. Bienkowski, P., Piasecki, J., Koros, E., Stefanski, R. \& Kostowski, W. Studies on the role of nicotinic acetylcholine receptors in the discriminative and aversive stimulus properties of ethanol in the rat. Eur. Neuropsychopharmacol. 8, 79-87 (1998).

77. Le Houezec, J., Jacob, P. 3rd. \& Benowitz, N. L. A clinical pharmacological study of subcutaneous nicotine. Eur. J. Clin. Pharmacol. 44, 225-230. https://doi.org/10.1007/BF00271362 (1993).

78. Matta, S. G. et al. Guidelines on nicotine dose selection for in vivo research. Psychopharmacology 190, 269-319. https://doi. org/10.1007/s00213-006-0441-0 (2007).

79. Hwa Jung, B., Chul Chung, B., Chung, S. J. \& Shim, C. K. Different pharmacokinetics of nicotine following intravenous administration of nicotine base and nicotine hydrogen tartarate in rats. J. Control Release 77, 183-190. https://doi.org/10.1016/s0168 $-3659(01) 00452-7(2001)$.

80. Swanson, L. W. Brain maps 4.0-Structure of the rat brain: An open access atlas with global nervous system nomenclature ontology and flatmaps. J Comp Neurol 526, 935-943. https://doi.org/10.1002/cne.24381 (2018).

\section{Author contributions}

G.C.L. and P.J.M. designed experiments, G.C.L. and C.P.K. conducted experiments and analyzed data; G.C.L., C.P.K., and P.J.M. wrote the manuscript.

\section{Funding}

This work was supported by National Institutes of Health grants DA048336 to G.C.L. and AA024112 to P.J.M and University at Buffalo start-up funds to G.C.L.

\section{Competing interests}

The authors declare no competing interests. 


\section{Additional information}

Correspondence and requests for materials should be addressed to P.J.M.

Reprints and permissions information is available at www.nature.com/reprints.

Publisher's note Springer Nature remains neutral with regard to jurisdictional claims in published maps and institutional affiliations.

(c) (1) Open Access This article is licensed under a Creative Commons Attribution 4.0 International License, which permits use, sharing, adaptation, distribution and reproduction in any medium or format, as long as you give appropriate credit to the original author(s) and the source, provide a link to the Creative Commons licence, and indicate if changes were made. The images or other third party material in this article are included in the article's Creative Commons licence, unless indicated otherwise in a credit line to the material. If material is not included in the article's Creative Commons licence and your intended use is not permitted by statutory regulation or exceeds the permitted use, you will need to obtain permission directly from the copyright holder. To view a copy of this licence, visit http://creativecommons.org/licenses/by/4.0/.

(C) The Author(s) 2021 